\title{
XXVII. A high-pressure electric accumulator or secondary battery
}

\section{Frederick John Smith}

To cite this article: Frederick John Smith (1883) XXVII. A high-pressure electric accumulator or secondary battery , Philosophical Magazine Series 5, 15:93, 203-204, DOI: $10.1080 / 14786448308628456$

To link to this article: http://dx.doi.org/10.1080/14786448308628456

册 Published online: 28 Apr 2009.

Submit your article to this journal

Џ Article views: 2

Q View related articles $₫$ 
plate $A$ than to the plate $B$ (for the surface must be symmetrical on opposite sides of this line). It is also evident, on account of this symmetry, that if, keeping $B$ fixed, we could transfer the plate $A$ to the position $A^{\prime}$ at an equal distance at the other side of the point $F$, the surface of equilibrium $\mathrm{GE}^{\prime}$ would be the same, and that there would again be no tendency to horizontal motion; for, $K^{\prime} E^{\prime}$ being equal to $K \mathrm{E}$, the hydrostatic tension on the plate $\mathbf{A}^{\prime}$ would counterbalance the diminution of the horizontal component of the surfacetension. If the plate $\mathrm{A}^{\prime}$ were now pushed nearer to $\mathrm{B}$, the horizontal component of the surface-tension between them would remain the same, owing to the constancy of the contactangles, while the hydrostatic tension would increase as the liquid rose between the plates and the curvature of its surface increased. Consequently, at all distances less than that referred to there will be attraction. (The case is indeed the same as that of fig. 3 , with the difference that the lowest element of the meniscus is inclined to the horizontal.)

If, on the other hand, the plate A be withdrawn from the position $\mathrm{A}^{\prime}$, the liquid between the plates will fall and the hydrostatic tension diminish, while the horizontal component of the surface-tension will remain the same till the line of contact with the plate A reaches the level of the free exterior surface, when it must become the line of contrary flexure, to which in all its positions we give the name F. Up to this position the repulsion will accordingly increase; after this it will diminish, since the inclination to the horizontal at $\mathrm{F}$ will diminish as $\mathrm{A}$ recedes further.

$$
\begin{aligned}
& \text { I am, Gentlemen, } \\
& \text { Your obedient servant, } \\
& \text { Clifton College, Bristol, } \\
& \text { Feb. 10, } 1883 . \\
& \text { A. M. Worthington. }
\end{aligned}
$$

XXVII. A High-Pressure Electric Accumulator or Secondary Battery. By Frederick JoHn SMith *.

THHE modification of the gas-battery of Sir W. Grove 1 which the author has devised is as follows:-The gasbattery of Sir W. Grove, as usually made, when used as an accumulator, owing to the small quantity of gases that it holds, soon runs down when in use. In order to make its life longer, the author puts the gases under a high pressure; by this means a large quantity of gas can be stored in a suitably constructed instrument. The earliest form of battery, and

* Communicated by the Author. 
this has been at work (i.e. has been charged and discharged as an accumulator) for eighteen months, is shown in the cut. A is a strong lead vessel, well lined with rubber varnish, to prevent any solution of the lead being formed. $\mathrm{O}, \mathrm{H}$, are platinized platinum cylinders, in inverted tubes held in their proper position by pieces of rubber. $\mathrm{M}$ is a manometer. The terminals $\mathrm{B}, \mathrm{C}$ are brought through insulating stoppers. A 10-per-cent. mixture of sulphuric acid and water is used as the liquid. With this arrangment a pressure

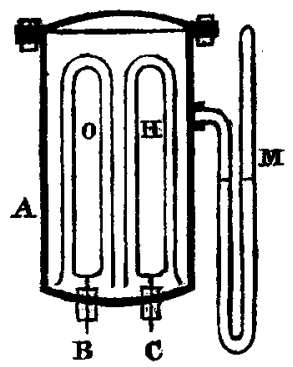
of seven atmospheres can be easily used; and thus the tubes, one of which has twice the capacity of the other, can contain 64 times the gas that they would do at the usual pressure. A second form has been made by Messrs. Becker Co., for the anthor. In this a U-shaped glass tube is used, the manometer being attached to the bend, and the sheets of platinum being fused into each leg. This form, although well suited for lecturepurposes, will bear but a small pressure. A curious point observed, and one that is now being carefully worked out, is that the E.M.F. appears to vary much with the pressure.

The author has, in addition to the experiment described, charged small Faure or lead secondary batteries under pressure, the result being that the life of the battery is lengthened by being charged under pressure. Sufficient data have not as yet been collected concerning the variation of the E.M.F. under pressure, and the behaviour of the lead battery under pressure, to put into print. Should others experimentalize in the direction of high-pressure accumulators, a caution must be added with regard to the air-space left in the lead chamber: that quantity of air must be left which may be compressed, say, to seven atmospheres of pressure before the gas in 0 rises outside.

Oxygen produced by electrolytic action almost instantly acts on the best India-rubber tubing or varnish, causing splits and cracks to be formed in it. The chambers are now made of lead to which a harder metal has been added.

Taunton, Feb. 15, 1883. 